\title{
Plantas medicinais como proposta interdisciplinar no segundo segmento da educação de jovens e adultos
}

\author{
Medical plants as proposed interdisciplinary in youth education second segment and adult. \\ Divino Oliveira Silva ${ }^{1}$, Eliane Maria Santos da Cruz ${ }^{1}$, Arnaldo Gonçalves de Campos², Leandro \\ Carbo $^{2}$, Maria das Graças Campos ${ }^{3}$ \\ ${ }^{1}$ Graduado (a), Instituto Federal de Educação, Ciência e Tecnologia de Mato Grosso - Campus São Vicente - Núcleo \\ Avançado de Jaciara, MT, Brasil. \\ 2 Professor, Instituto Federal de Educação, Ciência e Tecnologia de Mato Grosso - Campus São Vicente - Núcleo Avançado \\ de Jaciara, MT, Brasil. \\ 3 Professor Doutor, Departamento de Pós-Graduação, Universidade de Cuiabá - UNIC, Cuiabá, MT, Brasil
}

\begin{abstract}
Resumo
Este trabalho apresenta resultados de um estudo desenvolvido com os alunos da Educação de Jovens e Adultos (EJA) da Escola Antônio José de Lima, município de Juscimeira - Matos Grosso sobre o tema Plantas Medicinais (PM). O principal objetivo desta análise foi conhecer os saberes dos alunos a respeito da temática, procurando valorizar estes conhecimentos como instrumento interdisciplinar de ensino entre as disciplinas de biologia, química física e matemática. A pesquisa ocorreu durante o período de novembro de 2013 a setembro de 2014 . O desenvolvimento metodológico procedeu-se em etapas alternadas da seguinte forma: inicialmente realizou-se uma entrevista para diagnosticar o conhecimento prévio dos alunos acerca do assunto. Numa segunda etapa, foram ministradas aulas interdisciplinares, buscando integrar o tema sob a ótica do universo dos alunos, abordando conhecimentos das quatro disciplinas propostas. Os resultados alcançados na pesquisa demonstraram que os alunos possuíam um bom conhecimento prévio sobre o assunto, e que, esse aspecto favoreceu o trabalho interdisciplinar, pois quando as atividades foram aplicadas, esses alunos se prontificavam a participar ativamente e a responder a todos os questionamentos e discussões abordadas. Dessa forma, o tema PM se confirmou positivamente como uma boa opção na proposta da interdisciplinaridade para o ensino da EJA, pois os alunos demonstraram perseverança e dedicação em todas as atividades propostas.
\end{abstract}

Palavras-chave: EJA. Ensino de Ciências. Interdisciplinaridade.

\begin{abstract}
This paper presents results of a study conducted with students of the Youth and Adult Education (EJA) School of Antonio José de Lima, city of Juscimeira - Matos Grosso, on the topic Medicinal Plants (PM). The main objective of this analysis was to identify the knowledge of students on the theme, seeking to enhance this knowledge as an interdisciplinary tool for teaching, between the disciplines of biology, physics, chemistry and mathematics. The survey took place during the period from November 2013 to September 2014. The methodological development proceeded in alternating steps as follows: initially held an interview to diagnose students' prior knowledge on the subject. In a second step, interdisciplinary lessons were taught, seeking to integrate the topic from the perspective of the students' universe, abordando knowledge of the four disciplines proposals. The outcomes of the research showed that the students had a good prior knowledge of the subject, and that this aspect favored interdisciplinary work, for when the activities were applied, these students to actively participate and answer all the questions and discussions addressed. Thus, the PM theme was confirmed positively as a good option in the proposed interdisciplinary approach to teaching adult education, as students demonstrated perseverance and dedication in all the activities proposed.
\end{abstract}




\section{Introdução}

O presente trabalho aborda o uso de plantas medicinais (PM) no âmbito escolar, como instrumento de aprendizagem no ensino de Ciências. Neste sentido, foram organizadas atividades de ensino e pesquisa objetivando valorizar os saberes dos alunos de EJA a respeito das plantas medicinais para estudar as possibilidades de inserção do tema na prática do ensino de ciências.

$\mathrm{O}$ uso de PM, designadamente para fins medicinais surgiu com as sociedades primitivas. O conhecimento científico em muito tem se expandido, contudo ainda existem muitas pessoas que recorrem a métodos alternativos para curar determinadas doenças usando plantas. Isso talvez aconteça em virtude dos elevados custos dos remédios industrializados e/ou pela facilidade em se obter essas plantas.

Para Amico (2013) "PM são todas aquelas que possuem princípios ativos que ajudam no tratamento das doenças podendo levar até mesmo a sua cura".

A prática da interdisciplinaridade tem como intenção colaborar na reorganização do conhecimento partindo de uma dinâmica investigativa que envolve a participação de diferentes disciplinas sobre um eixo integrador, que propicie a necessidade de trabalhar em conjunto (SILVA, 2012).

Fazenda (2008) define "interdisciplinaridade como atitude de ousadia e busca frente ao conhecimento, cabe pensar aspectos que envolvem a cultura do lugar onde se formam professores. Portanto, torna-se fundamental a articulação dos conteúdos a partir de um tema de interesse que possa garantir maiores aprofundamentos, e trocas de experiências entre professores e alunos, quando o grande desafio da proposta educativa de EJA seriar construir um Projeto Político Pedagógico diferenciado do Ensino Regular, para inserir os alunos no processo de aprendizagem com autoria, participação e protagonismo.

O interesse pelas PM surgiu após a realização de uma pesquisa junto à população Juscimeirense para avaliar as plantas mais conhecidas e plantadas pela população da cidade.

Assim o conhecimentos dos alunos podem sinalizar os objetivos e possibilidades metodológicas que venham aprimorar o ensino para quem não teve a oportunidade de estudar na idade propícia. Mediante os preceitos legais, nesta fase da escolarização, os currículos e projetos escolares devem respeitar a cultura e características inerentes aos jovens, que possuem conhecimentos necessários a construção de uma proposta educativa que reflita e dialogue com os saberem que estes alunos vem acumulando ao longo da vida

Desta forma, a pesquisa foi desenvolvida com os alunos da $1^{\underline{a}}$ fase do $2^{\underline{o}}$ segmento da EJA, que corresponde ao $6^{0}$ e $7^{0}$ ano do Ensino Fundamental, na Escola Antônio José de Lima no município de Juscimeira. A clientela dessa escola caracteriza-se por filhos de trabalhadores rurais, canavieiros, donas de casas, trabalhadores autônomos, motoristas e funcionários públicos na faixa etária de 6 a 14 
anos no Ensino Fundamental / Ciclo de Formação Humana e acima de 16 anos na Modalidade EJA, de classe econômica baixa e média.

As praticas desenvolvidas pelos alunos certamente irão contribuir para a melhoria dos conhecimentos a respeito das plantas medicinais e consequentemente a apropriação deste conhecimentos para melhorar a qualidade de vida e de saúde da população de Juscimeira, que tradicionalmente é composta por pequenos agricultores, sendo a sua terra fértil a principal atração para a instalação de seus primeiros habitantes em 1957 ás margens do Rio Areia e da Rodovia 364.

Os estudos reafirmam os postulados de que nos dias atuais o que se sabe sobre PM provém principalmente do conhecimento popular e de pesquisas etnobotânicas. O uso de medicamentos caseiros para curar moléstias como gripes, problemas de digestão, resfriados, dentre outros. Esse hábito de se usar as PM é considerado uma tradição passada de geração em geração ao longo do tempo.

Conforme postulados que reafirmam a necessidade de maiores articulações dos conhecimentos e dos saberes acumulados pelos alunos ao longo da vida o tema PM, foi adotado como instrumento interdisciplinar de aprendizado para a $1^{\text {a }}$ fase do 2o segmento da Educação de Jovens e Adultos da escola Antônio José de Lima do município de Juscimeira - MT.

Por intermédio da familiarização com o tema PM esse assunto foi escolhido como objeto de estudo e especialmente pelo fato de muitos docentes evidenciarem a falta de material didático/pedagógico para se trabalhar com o público EJA.

Partindo do pressuposto que o aluno da EJA já tenha conhecimento prévio da medicina popular, o tema: Plantas Medicinais como proposta interdisciplinar no segundo segmento da Educação de Jovens e Adultos da escola Antônio José de Lima MT é proposto como instrumento de ensino buscando contribuir com uma aprendizagem significativa. "A aprendizagem é muito mais significativa à medida que o novo conteúdo é incorporado às estruturas de conhecimento de um aluno e adquire significado para ele a partir da relação com seu conhecimento prévio" (PELIZZARI et al 2002).O objetivo geral do presente trabalho foi: Pesquisar conhecimentos populares sobre as PM com o público da EJA, bem como socializar os respectivos conhecimentos.

Como objetivo específico teve-se os seguintes:

$>$ Diagnosticar os saberes dos alunos e relacioná-los aos conteúdos abordados em Ciências;

> Elaborar e desenvolver aulas interdisciplinares;

> Realizar oficina com PM entre os alunos e a comunidade escolar;

> Identificar e nomear as partes das plantas usadas para fins medicinais;

$>$ Compreender a relação da importância do tema para a vida, e;

$>$ Desenvolver atividade lúdica intencionando avaliar o nível de aproveitamento do trabalho realizado. 


\section{Metodologia}

Os processos metodológicos dessa pesquisa fundamentaram se na abordagem qualitativa tipo exploratório. Gil (2002) afirma que "nas pesquisas qualitativas, o conjunto inicial em geral é reexaminado e modificado sucessivamente, com vista em obter ideais mais abrangentes e significativos". A utilização desse método de pesquisa possibilitou uma reflexão e o levantamento das opiniões dos alunos sobre o uso das plantas medicinais.

O primeiro método utilizado foi à realização de um levantamento bibliográfico que continuou ao longo de todo trabalho. Esse procedimento possibilitou a ampliação do conhecimento teórico, bem como a fundamentação dos pontos importantes que permearam o estudo. As principais fontes enfocadas foram: livros; publicações; artigos; textos on-line; revistas reforçando dessa forma a compreensão da questão em pauta.

Para a coleta de dados utilizou-se entrevistas com uso de gravadores, para levantar informações sobre o nível de conhecimento e o envolvimento com o tema. A entrevista foi realizada a fim de levantar informações sobre os conhecimentos populares dos alunos da EJA, onde individualmente, responderam perguntas relacionadas a dados pessoais como sexo, idade $\mathrm{O}$ período da realização desta pesquisa de novembro de 2013 a setembro de 2014 na Escola Estadual de Ensino Fundamental e EJA, "Antônio José de Lima" situada na Rua Emanuel Pinheiro, no 183, na cidade de Juscimeira, Estado de Mato Grosso.

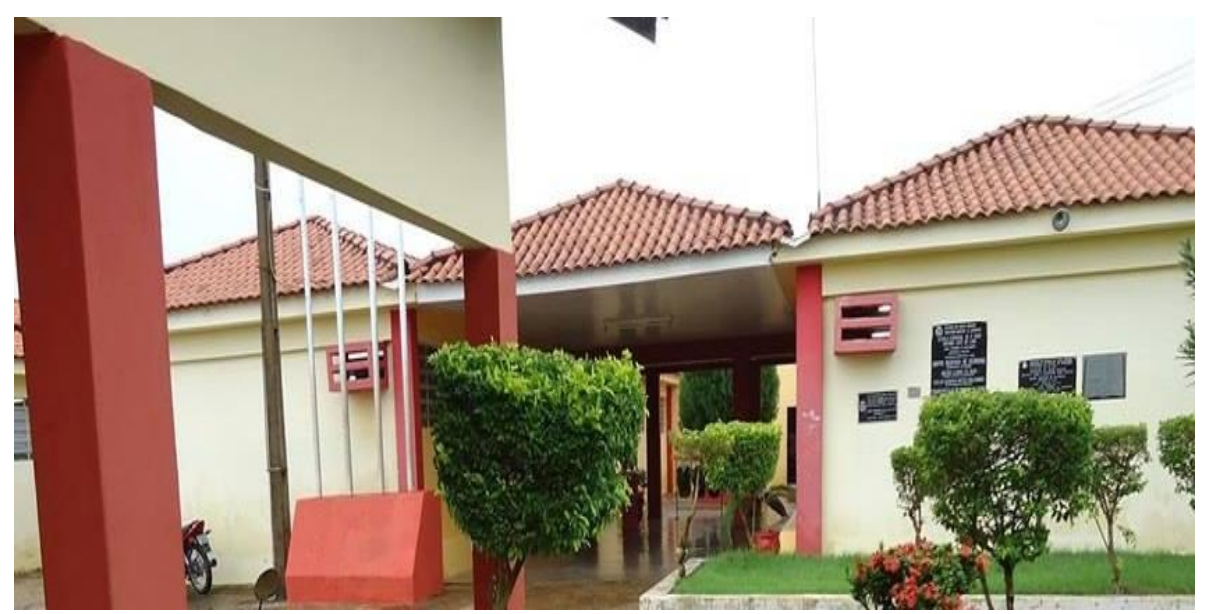

Figura01 - Escola onde foi realizada a intervenção

A partir dos resultados das entrevistas e para ampliar os conhecimentos sobre o tema, algumas aulas foram ministradas utilizando se de alguns recursos didáticos, quadro, giz, trilha pedagógica, data show abordando a interdisciplinaridade em biologia, física, matemática e química.

Abordagem interdisciplinar: na Biologia o foco foi as Plantas Medicinais bem como aquelas que se utilizadas de maneira incorreta podem causar danos à saúde e as 
consideradas tóxicas ao organismo humano, bem como também as partes principais das plantas, a fotossíntese, nome popular e nome científico. Na química, as substâncias que compõe as plantas medicinais dando a ela o efeito curador, ou seja, o princípio ativo. $\mathrm{Na}$ física, foram trabalhadas a formas de conservar e guardar essas plantas, utilizando se de um método bem prático com a secagem das plantas. E na matemática viu se a importância da dosagem correta na fabricação dos chás, pois a diferença entre remédio e veneno na maioria das vezes é a dose.

As aulas expositivas foram realizadas no período de 5 de maio a 17 de junho de 2014 sendo trabalhado três aulas semanais. O início das aulas conforme o horário escolar inicia-se ás 18: $20 \mathrm{~h}$ e segue $21: 30 \mathrm{~h}$.

Durante as aulas foi proposta uma oficina de PM onde cada aluno ficou responsável em levar um exemplar de alguma planta com fins terapêuticos com a confecção de cartazes reportando sua indicação, parte utilizada, e qual a forma de preparo do medicamento.

Após a realização dessa oficina, foi realizado um "QUIZ" contendo 32 perguntas com intenção de identificar o nível de aproveitamento do trabalho. O QUIZ é uma atividade que permite o aluno descontrair uma pouco na sala de aula e serve como avaliação de aprendizagem. Carvalho et al (2010) define QUIZ como uma espécie de jogo de perguntas e resposta, que pode proporcionar aos participantes uma experiência envolvente usando elementos de disputas. Este recurso pode representar uma importante ferramenta no processo de ganho de autonomia e valorização de diferentes formas de aprendizagem dos alunos.

\section{Resultados e discussão}

Os resultados obtidos através das entrevistas em relação ao gênero demonstraram que dos trezes alunos entrevistados, $69 \%$ são do sexo feminino e $30,76 \%$ são do sexo masculino (TAB.1) com faixa etária entre 30 e 68 anos.

TABELA 1: Percentual em relação ao gênero dos alunos entrevistados

\begin{tabular}{lll}
\hline Sexo & Quantidade & Percentual \\
\hline Masculino & 4 & $30,76 \%$ \\
Feminino & 9 & $69,24 \%$ \\
\hline \hline Total & 13 & $100 \%$ \\
\hline
\end{tabular}

Fonte: Dados da pesquisa. 2014

Segundo uma pesquisa realizada pelo IBGE no ano de 2007, 54\% dos alunos da EJA são mulheres, frequentando principalmente o segundo segmento do ensino fundamental. Durante grande parte da história as mulheres, tiveram o acesso restrito a escolarização, elas eram educadas para ser mãe, esposa e a fazer trabalhos domésticos. No entanto, para Soek et. al, (2009), no decorrer dos anos as mulheres tem se inserido no mercado de trabalho e com isso tem buscado a escolarização. 


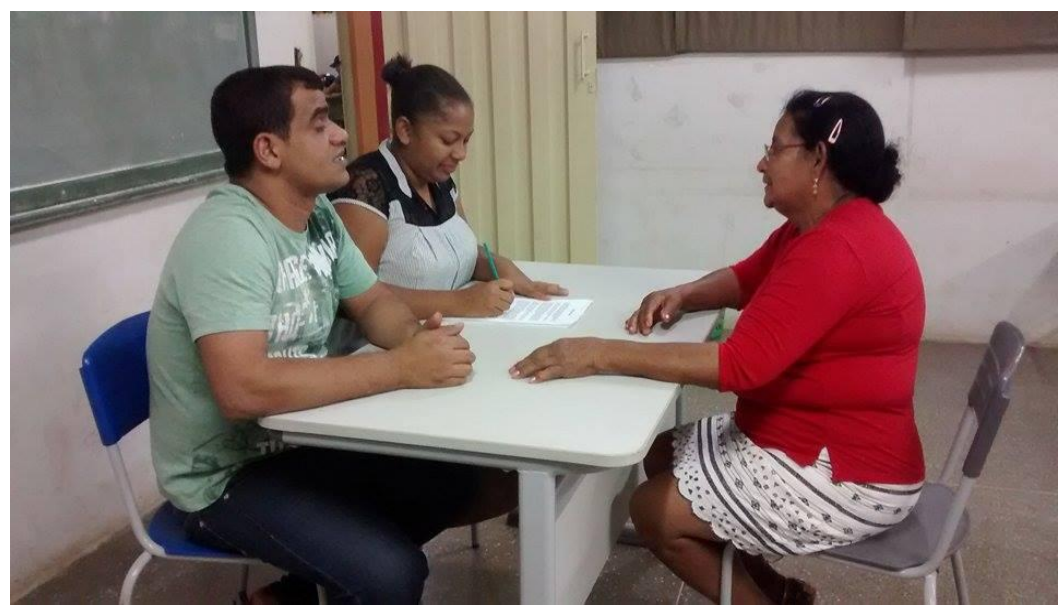

Figura 02 - Aluna da EJA sendo entrevistada

Ao serem questionados sobre o tema PM os alunos da EJA demonstraram vivenciar essa realidade em seu cotidiano. Para constatar esse fato foi perguntado ainda se os mesmos sabiam o que são PM 69,23 \% afirmaram positivamente que sim, inclusive alguns alunos citaram exemplos de plantas com fins medicinais (GRÁF.1).

GRÁFICO 1 - Percentual do conhecimento sobre PM

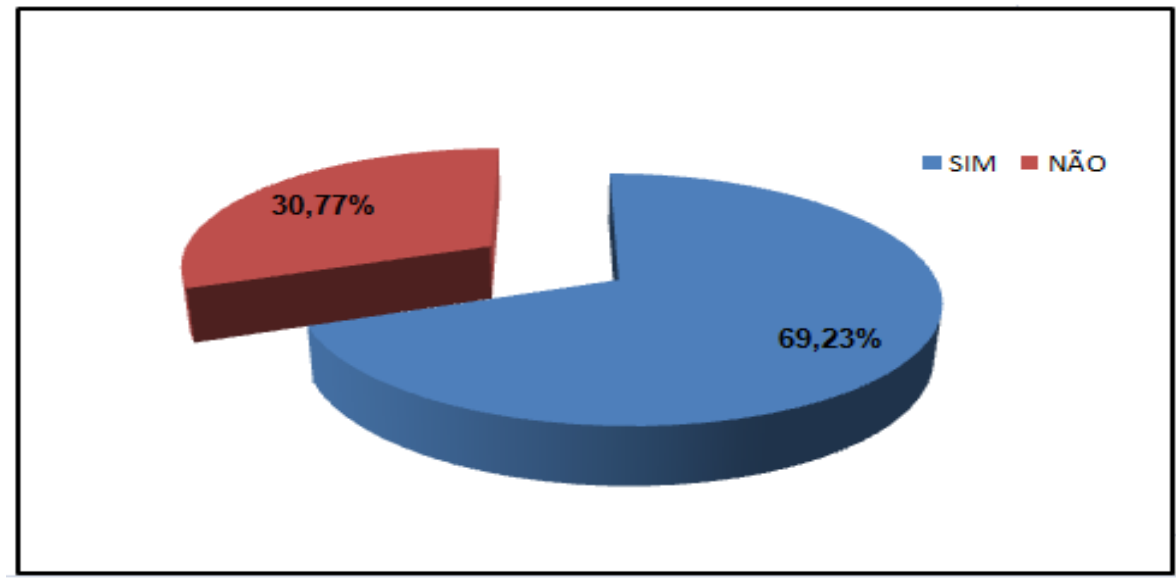

As plantas que foram citadas pelos alunos nas entrevistas estão descritas na tabela 02. 
Tabela 2: Percentual das espécies de PM citadas pelos alunos da EJA

\begin{tabular}{|c|c|c|c|c|}
\hline NOME POPULAR & NOME CIENTÍFICO & FAMÍLIA & FREQÜÊNCIA & PERCENTUAL \\
\hline Alfavaca & Ocimum basilicum & Lamiaceae & 3 & $3,80 \%$ \\
\hline Acerola & Malpighia glabra & Malpighiaceae & 1 & $1,27 \%$ \\
\hline Alecrim & Rosmarinus officinalis & Lamiaceae & 1 & $1,27 \%$ \\
\hline Algodão & Gossypium hirsutum & Malvaceae & 1 & $1,27 \%$ \\
\hline Alho & Allium sativum & Alliaceae & 1 & $1,27 \%$ \\
\hline Babosa & Aloe vera & Asphodelaceae & 1 & $1,27 \%$ \\
\hline \multirow[t]{2}{*}{ Barbatimão } & Stryphnodendron & Fabaceae & 1 & \\
\hline & adstringens & & & $1,27 \%$ \\
\hline Boldo & Plectranthus barbatus & Lamiaceae & 5 & $6,33 \%$ \\
\hline Caferana & Tachia guianensis & Gentianaceae & 3 & $3,80 \%$ \\
\hline Cajá & Spondias mombin & Anacardiaceae & 1 & $1,27 \%$ \\
\hline Camomila & Matricaria recutita & Asteraceae & 2 & $2,53 \%$ \\
\hline \multirow[t]{2}{*}{ Canela } & Cinnamomum & Lauraceae & 1 & \\
\hline & zeylanicum & & & $1,27 \%$ \\
\hline Capim Cidreira & Cymbopogon citratus & Poaceae & 9 & $11,39 \%$ \\
\hline Colônia & Alpinia zerumbet & Zingiberaceae & 1 & $1,27 \%$ \\
\hline Couve & Brassica oleracea & Brassicaceae & 1 & $1,27 \%$ \\
\hline Crista de Galo & Celosia argêntea & Amaranthaceae & 1 & $1,27 \%$ \\
\hline Erva Cidreira & Melissa officinalis & Lamiaceae & 6 & $7,59 \%$ \\
\hline Gengibre & Zingiber officinal & Zingiberaceae & 1 & $1,27 \%$ \\
\hline Guapo & Mikania glomerata & Asteracea & 1 & $1,27 \%$ \\
\hline Guiné & Petiveria alliacea & Phytolaccaceae & 2 & $2,53 \%$ \\
\hline Hortelã & Mentha spicata & Lamiaceae & 9 & $11,39 \%$ \\
\hline Hortelã Gorda & Coleus amboinicus & Lamiaceae & 4 & $5,06 \%$ \\
\hline Jiló & Solanum gilo & Solanaceae & 1 & $1,27 \%$ \\
\hline Laranja & Citrus sinensis & Rutaceae & 1 & $1,27 \%$ \\
\hline Lima & Citrus limettioides & Rutaceae & 1 & $1,27 \%$ \\
\hline Limão & Citrus limon & Rutaceae & 2 & $2,53 \%$ \\
\hline Losna & Artemisia absinthium & Asteraceae & 1 & $1,27 \%$ \\
\hline Melancia & Citrullus lanatus & Cucurbitaceae & 1 & $1,27 \%$ \\
\hline Melão & Momordica charantia & Cucurbitaceae & 2 & \\
\hline Caetano & & & & $2,53 \%$ \\
\hline Mastruz & Coronopus didymus & Brassicaceae & 1 & $1,27 \%$ \\
\hline None & Morinda citrifolia & Rubiaceae & 1 & $1,27 \%$ \\
\hline Ora Pro Nobis & Portulaca oleracea & Portulacaceae & 1 & $1,27 \%$ \\
\hline Poejo & Mentha pulegium & Lamiaceae & 5 & $6,33 \%$ \\
\hline Quina & Quassia amara & Simaroubaceae & 1 & $1,27 \%$ \\
\hline Sabugueiro & Sambucus nigra & Adoxaceae & 2 & $2,53 \%$ \\
\hline Seriguela & Spondias purpúrea & Anacardiaceae & 1 & $1,27 \%$ \\
\hline Terramicina & Alternanthera brasiliana & Cucurbitaceae & 1 & $1,27 \%$ \\
\hline Vick & Mentha arvensis & Lamiaceae & 1 & $1,27 \%$ \\
\hline TOTAL & & & 79 & 100\% \\
\hline
\end{tabular}


Entre todas as plantas citadas pelos alunos, foi verificado que capim cidreira e hortelã foram as espécies maior frequência, indicadas respectivamente como calmante e resfriado.

GRÁFICO 02 - Percentual de utilização das PM pelos entrevistados

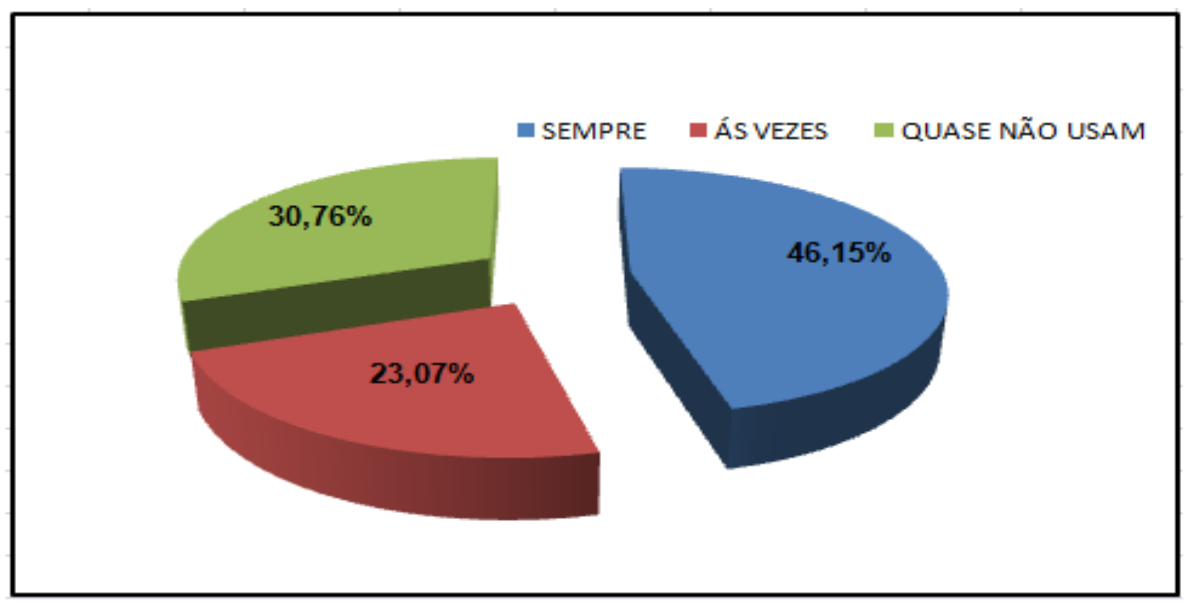

Quando questionados sobre a utilização das PM 76,92\% disseram que utilizam essas plantas. Em relação às diversas formas de utilização das mesmas foram identificadas como (Infusão, decocção, banho, maceração e sucos, porém a mais frequente é em forma de chá (infusão), sendo as folhas $(92,3 \%)$ a parte mais utilizada para a preparação dos chás. A frequência de uso das PM pelos alunos da EJA varia entre sempre (46,15\%), às vezes $(23,07 \%)$ ou quase não usam (30,76\%). A maioria dos entrevistados relatou que cultiva alguma espécie medicinal em casa, e o conhecimento sobre as plantas adquiriram entre os familiares, ou seja, essa cultura tem sido passada de geração a geração.

Gráfico 03 - Percentual sobre o conhecimento de efeito colateral das PM

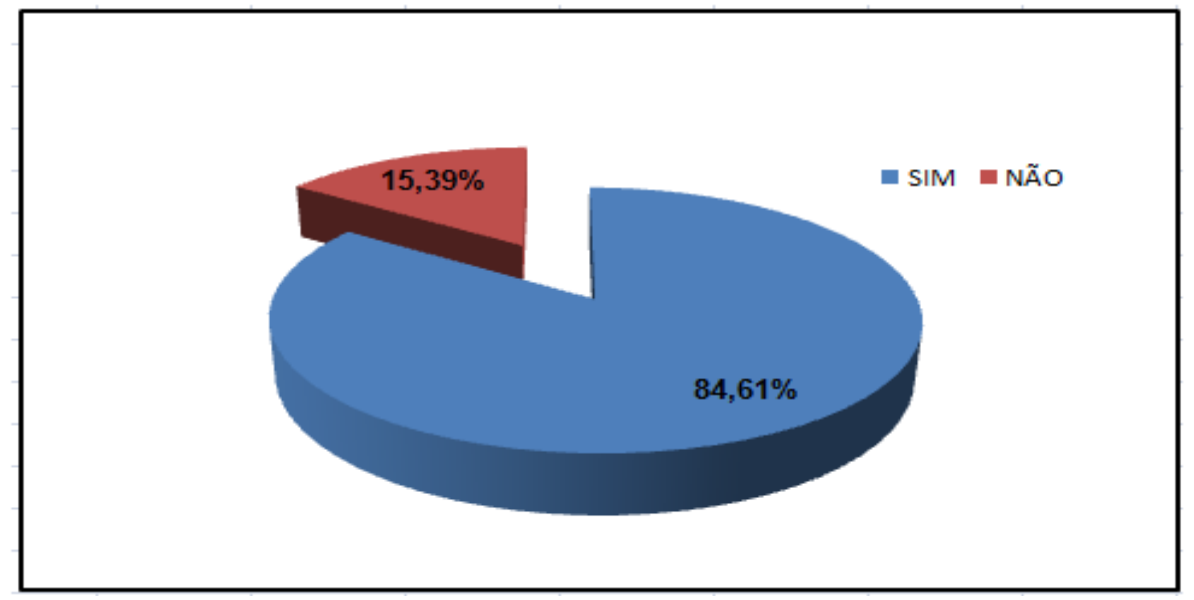

Quando esses alunos foram questionados sobre o conhecimento de algum efeito colateral que tenha ocorrido com alguém próximo e/ou mesmo distante $84,61 \%$ responderam que até o momento nunca tinham ouvido falar sobre intoxicação com plantas medicinais 
(Figura 03), e 100\% afirmaram que a utilização de chás com PM é recomendada que se tome no dia preparado.

Considerando o conhecimento desses alunos, nota-se que esse tema é relevante para se promover um projeto em educação. Pois sugere uma maneira de trazer o conhecimento prévio desses alunos para a sala de aula e com isso abordar conteúdos das áreas de Biologia, Química, Física e Matemática, que podem ter ligações entre si, mas que talvez tenham sido tratados de modo abstrato, não trazendo nenhum sentido aos alunos da EJA.

Após as entrevistas, em outra oportunidade, voltou-se a escola para observar uma aula sendo ministrada na EJA. Essa visita veio com o objetivo de averiguar o funcionamento das aulas na EJA, bem como observar como as atividades eram desenvolvidas, quais as dificuldades existentes, entre outros. Para tanto, a observação não se restringiu somente em um dia, pois durante todo o decorrer da intervenção as atuações dos alunos foram observadas.

A intervenção foi pensada com o objetivo de ser realizada em no máximo quatro aulas, contudo observou se que trabalhar com a EJA exige um pouco de paciência, pois os conteúdos devem ser trabalhados bem mais devagar porque o desenvolvimento na sala é um pouco lento.

De maneira geral, observou se que os alunos estavam bem interessados em aprender. Tudo que foi proposto eles realizaram com êxito e o funcionamento das aulas foi bem tranqüilo. Os alunos questionavam, participavam e alguns mostraram dificuldades em transcrever atividades extensas no caderno, pois copiam devagar. Recursos didáticos foram desenvolvidos visando facilitar o processo de ensino-aprendizagem e para tornar as aulas mais dinâmicas e atrativas (FIG.3). Os recursos utilizados foram: atividades impressas (Cruzadinha, Caça Palavras), Slides, Quadro de Giz, trilha pedagógica, pois os recursos didáticos usados pela professora são os livros didáticos que só ela possui, pois o PNLD (Programa Nacional do Livro Didático) não enviou livros específicos para a EJA da referida escola.

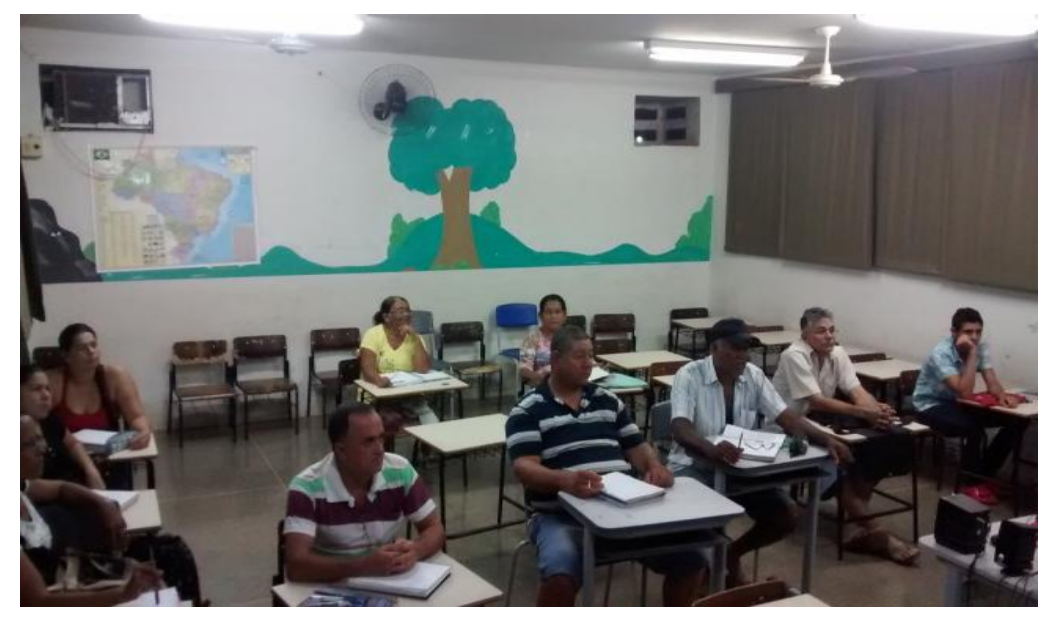

Figura 3 - Alunos participando das aulas sobre PM

De acordo com Costoldi e Polinarski (2009), "os recursos didáticos são de fundamental importância no processo de desenvolvimento cognitvo do aluno", ou seja, ajuda a ampliar a capacidade de observação, aproximando o aluno de sua realidade e permitindo com maior facilidade a fixação do conteúdo e consequentemente a 
aprendizagem, onde o educando poderá utilizar este conhecimento em situações do cotidiano.

Todos esses recursos foram bem aceitos pelos alunos da EJA. A utilização dos mesmos promoveu interação entre os mesmos, percebeu-se interesse e envolvimento com o tema, com isso ficou explícito um alto índice de aprendizagem. Mas um dos recursos utilizados ultrapassou as expectativas, a trilha pedagógica. Esta atividade foi feita no ultimo dia de aula antes das férias escolares, na quadra de esportes da escola e era composta de perguntas e informações sobre tema trabalho.

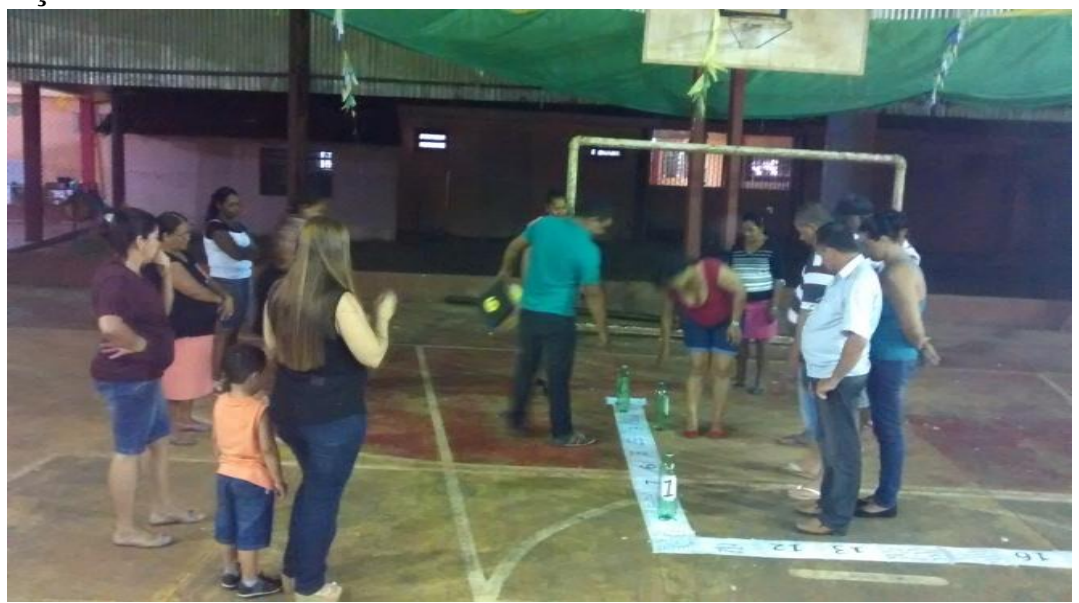

Figura 4 - Alunos participando da trilha pedagógica

O mais interessante da trilha e das outras atividades propostas, é que quase tudo era novo para os alunos, com isso eles reclamavam dizendo que não sabiam fazer, estavam com vergonha de fazer e/ou falar algo errado. No entanto, no decorrer da atividade a participação foi unânime e eles mostravam empolgação, entusiasmo e interesse. Em virtude disso esta atividade foi repetida três vezes no dia, pois um aluno disse que: "só paro de jogar quando ganhar" (FIG.4). As perguntas presentes na trilha foram respondidas corretamente e neste jogo venceria quem chegasse ao final da trilha primeiro. Isso mostra que com atividades diferenciadas além de promover uma interação entre os alunos, contribui para uma aprendizagem mais significativa. Pelizari et al (2002) diz que "quando se incorpora um novo conteúdo criando estratégias para que o aluno consiga adquirir o significado a partir do conhecimento prévio a aprendizagem é mais significativa.

Após as férias a intervenção prosseguiu por mais alguns dias. Uma oficina tinha sido proposta no início da intervenção onde cada aluno ficou responsável em trazer um exemplar de PM que cultivassem em casa ou que conhecessem seu efeito medicinal e confeccionar cartazes reportando: nome popular, nome científico, forma de preparo, parte da planta utilizada e indicação, bem como também explicar sobre a planta para os participantes da oficina.

Como cada aluno havia escolhido uma planta para apresentar, percebeu-se que era preciso buscar mais informações, pensando nisso agendou-se uma aula no LIED (Laboratório de Informática Educacional). Os alunos foram convidados a irem até o mesmo, com a proposta de pesquisarem sobre a planta escolhida por eles. Todas as informações levantadas foram descritas no caderno para poderem estudar para a oficina, alguns encontraram dificuldades no manuseio do computador, porém isso não os impediu de realizarem o objetivo principal da aula. 


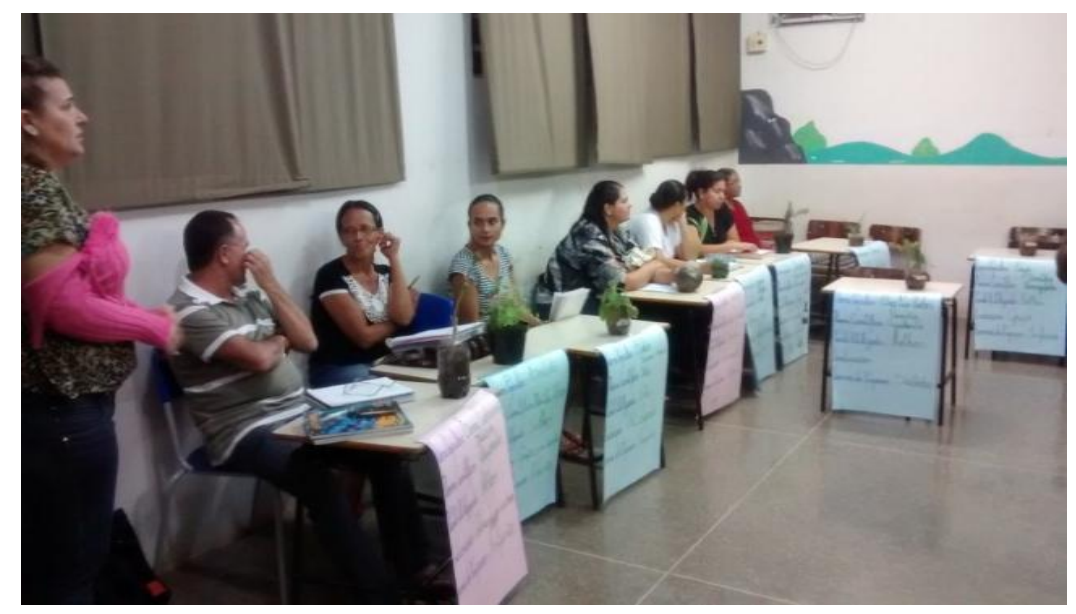

Figura 5 - Alunos preparados para iniciar a apresentação da oficina

Todas as turmas do noturno participaram da oficina totalizando 135 alunos. O trabalho foi organizado e apresentado por 3 professores e 13 alunos. Antes de dar início ás atividades algumas dúvidas surgiram por parte dos alunos. Entre as principais dúvidas manifestadas citam-se algumas tais como: como deveriam se portar como deveriam explicar (FIG.5). As respostas aos questionamentos feitos pelos alunos consistiram-se basicamente em explicar-lhes que só falariam aquilo que soubessem e que poderiam ler no caderno sobre o uso das plantas.

Logo após o início da apresentação das oficinas, os alunos das turmas convidadas começaram a chegar para participarem das atividades. Quando a primeira turma entrou na sala, os alunos que estavam apresentando (FIG.7) ficaram um pouco apreensivos e no olhar deles surgia um pedido de socorro, eles estavam com medo de errar, estavam presos aos cadernos, inclusive alguns gaguejavam nas explicações. Percebia se, portanto, que eles se encontravam bastante inseguros. Contudo todos estavam preparados para responder qualquer questionamento e tudo correu como o esperado.

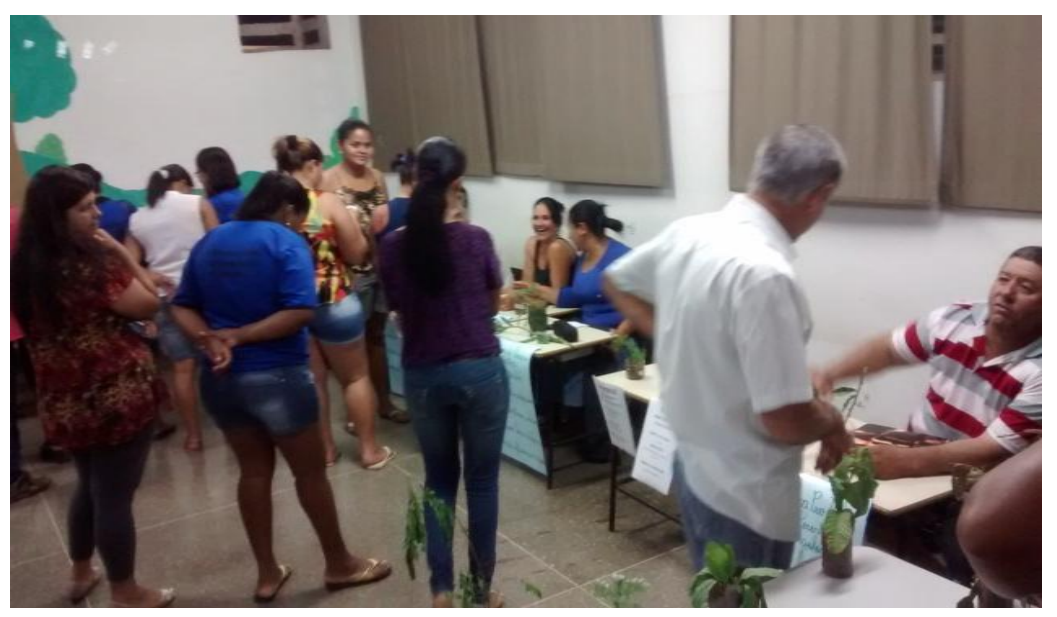

Figura 6: alunos prestigiando a oficina.

Quando as outras turmas participantes foram se aproximando (Figura 6), os apresentadores da atividade já estavam mais tranquilos, houve troca de informação entre os alunos, e percebeu-se a valorização de suas vivências, de seus conhecimentos que foram 
adquiridos principalmente de gerações anteriores, pais e avós (CAVAGLIER, 2011)

Uma das plantas apresentadas na oficina que chamou muito a atenção de todos foi o Ora Pro Nobis, pouco conhecida na região, mas que é bastante indicada para problemas digestivos de acordo com um aluno da EJA.

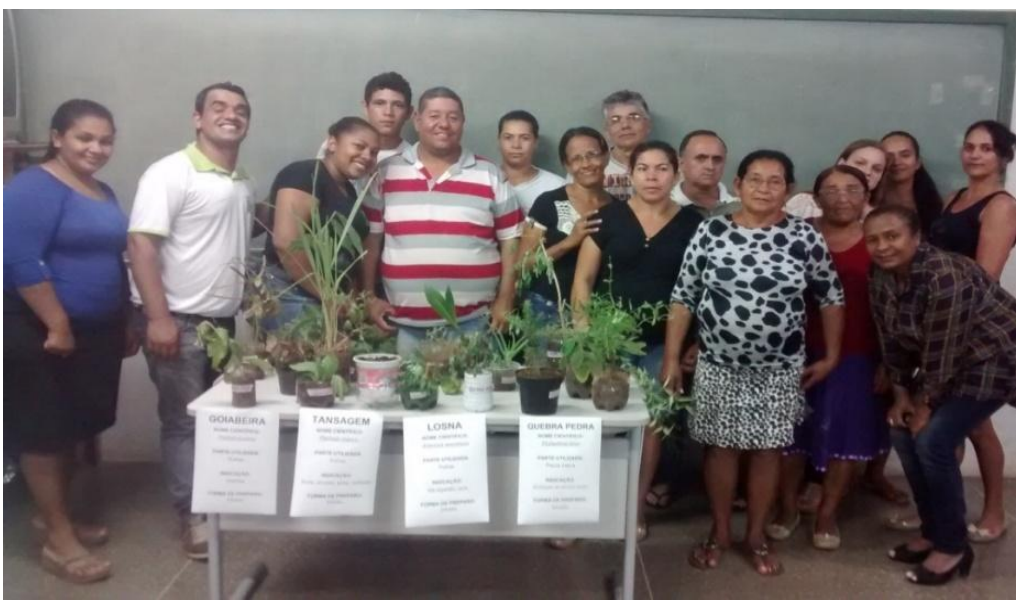

Figura 7 - Alunos que apresentaram a oficina

A receptividade dos alunos durante a apresentação da oficina foi bem mais calorosa com as últimas turmas em relação às primeiras, pois eles perceberam que estavam falando de algo que eles conheciam, algo presente na vida da maioria deles, com isso percebeu-se também, a valorização da auto-estima desse alunos ao finalizar o trabalho. Freire (1996), fala da importância de valorizar o conhecimento prévio desses alunos.

A oficina sobre PM demonstrou que ao trazerem conhecimentos importantes do seu cotidiano os alunos demonstraram capacidade e contribuíram significativamente para o aprendizado em sala de aula, tendo como conseqüência a valorização da auto-estima de todos os indivíduos envolvidos, direta ou indiretamente na atividade (FIG.7).

As principais plantas utilizadas pelos alunos na oficina foram: Erva Cidreira (Melissa officinalis), Hortelã (Mentha spicata), Boldo (Plectranthus barbatus), Cana de Macaco (Costus spicatus), Coco da Bahia (Cocos nucifera), Capim Cidreira (Cymbopogon citratus), Terramicina (Alternanthera brasiliana), Babosa (Aloe vera), Poejo (Mentha pulegium), Fedegoso (Senna occidentalis), Goiaba (Psidium guajava), None (Morinda citrifolia), Ora Pro Nobis (Portulaca oleracea), Acerola (Malpighia glabra), Alecrim (Rosmarinus officinalis), Tansagem, Anador, Camomila (Matricaria recutita), Mastruz (Coronopus didymus), Goiaba (Psidium guajava), Jurubeba (Solanum paniculatum) e Hortelã Gordo (Coleus amboinicus). Ao finalizar a oficina essas plantas foram plantadas na horta da escola pelo professor de matemática e pela professora de Ciências, juntamente com os alunos do período matutino.

Com intuito de averiguar se os conteúdos abordados anteriormente em sala de aula tinham sido bem absorvidos, procedeu-se a aplicação um QUIZ que foi realizado como atividade avaliativa após finalizar a intervenção. 


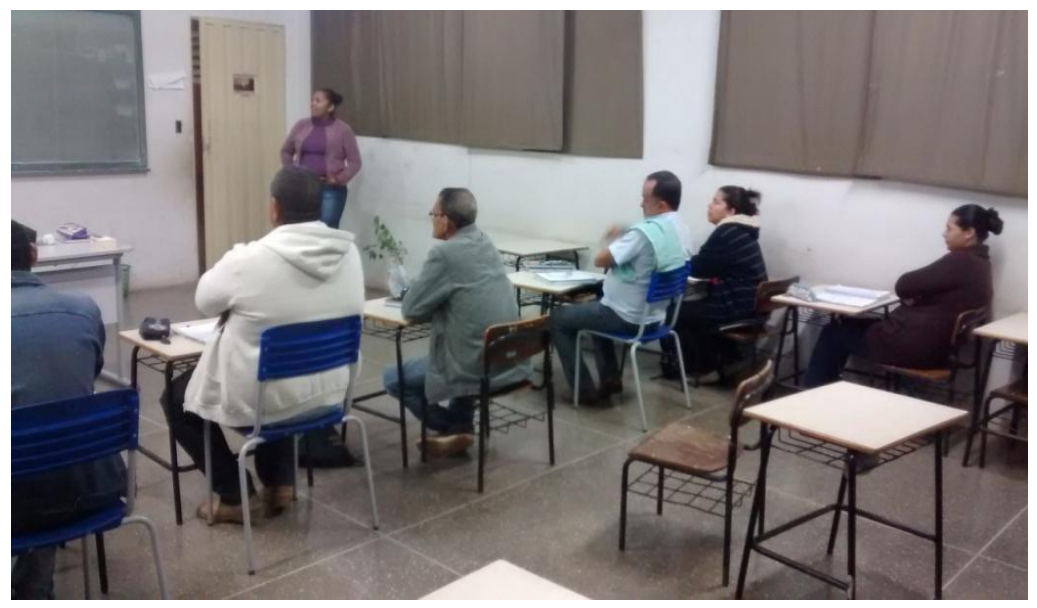

Figura 8: Alunos participando do QUIZ.

No dia da aplicação do QUIZ (FIG.8) os alunos ficaram tímidos, talvez por nunca terem realizados uma atividade como essa anteriormente, mas no decorrer da realização, os alunos foram se habituando. Participaram desta atividade seis alunos, divididos em dois grupos A e B. As perguntas eram aleatórias, onde algumas eram representadas por imagens, já as outras por textos. Das 32 questões 30 foram respondidas corretamente.

Como visto no GRÁF. 4 o índice de acerto no QUIZ foi significativamente alto, podendo concluir que os alunos entenderam o conteúdo.

GRÁFICO 4 - Percentual de acertos e erros no QUIZ

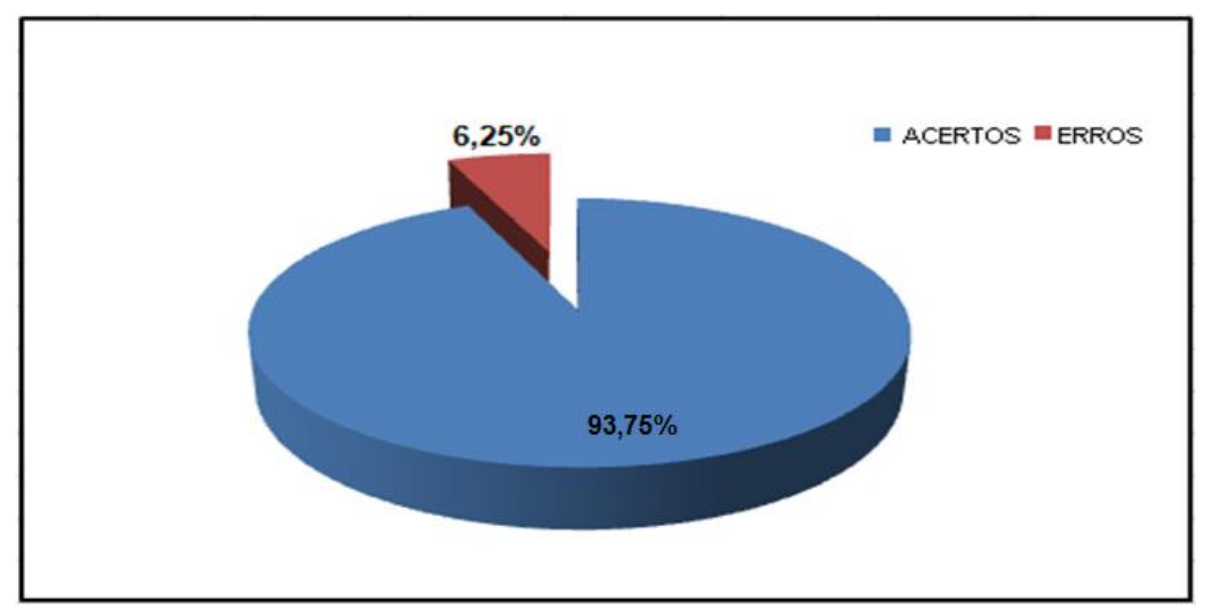

A intenção dessa intervenção era pesquisar o conhecimento popular sobre as PM e promover aulas interativas e dinâmicas abordando conceitos de Biologia, Física, Química e matemática visando uma ação interdisciplinar com os sujeitos da EJA visando alcançar uma aprendizagem mais significativa. Percebeu-se que com um pouco de esforço e dedicação é possível ensinar o aluno de uma forma simples na qual o mesmo esteja usando os conhecimentos que já possui.

Para Freire (1996), a alfabetização deve partir daquilo que o aluno já sabe, ou seja, do seu contexto ou da sua história de vida, ele reforça a função social do aprendizado, em um dos seus livros ele argumenta "a leitura de mundo precede a da 
palavra, daí que a posterior leitura desta não possa prescindir da continuidade da leitura daquela".

\section{Conclusão}

Para realizar este trabalho buscou-se analisar algumas das principais dificuldades encontradas no ensino de Ciências da EJA. Entre as principais dificuldades encontradas, a mais preocupante foi defrontar com poucas fontes teóricas literatura direcionada para esta modalidade. É importante ressaltar que os materiais didáticos existentes e as metodologias de ensino continuam sendo, em sua maioria, adaptações produzidas para atender aos objetivos do ensino regular. Diante da situação encontrada pensou-se em utilizar uma metodologia que pudesse ser trabalhada para atender a estes alunos.

O tema PM surgiu como proposta interdisciplinar, e que poderia ser facilitadora do processo de ensino-aprendizagem nas disciplinas de Física, Química, Matemática e Biologia. Após ministrar as aulas identificou-se que os alunos possuíam um conhecimento prévio do assunto, pois quando era aplicada alguma atividade neste sentido, os alunos se prontificavam a participar e a responder.

Ter trabalhado com o tema Plantas Medicinais na EJA foi muito prazeroso, pois os alunos participaram da aula, e as atividades propostas foram realizadas com perseverança e dedicação.A intervenção proporcionou uma nova perspectiva profissional, haja vista que a atividade ampliou os conhecimentos ao se aliar a teoria e a prática na construção dos saberes da docência, em relação à interação coletiva, e a maneira de ver o professor como orientador e pesquisador.

Ao termino da execução da atividade proposta conclui-se que o tema PM pode ser utilizado como ferramenta educacional para a proposição de atividades dentro do ensino de Ciências na EJA. Por fim percebeu-se que relação entre os sujeitos envolvidos no processo ensino aprendizagem (professor e alunos), é de suma importância para que estes se vejam como atores principais na construção de seus conhecimentos e por sua vez se interessem mais pelos conteúdos propostos para a disciplina.

\section{Agradecimentos}

À Coordenação de Aperfeiçoamento de Pessoal de Nível Superior (CAPES) pelo subsídio através do Programa de Consolidação das Licenciaturas (PRODOCENCIA) Edital 019/2013, processo № 113.657, e do Programa Institucional de Bolsa de Iniciação à Docência (PIBID) Edital № 061/2013, processo № 128.570, IFMT/Campus São Vicente/Sub Projeto Ciências.

\section{Referências}

AMICO, D. Para que servem as plantas medicinais 2013. Disponível em http://www.dihitt.com/barra/para-que-servem-as-plantas-medicinais. Acessado dia: 18/04/2014.

CAVAGLIER, M.C.‥ Plantas Medicinais na Educação de Jovens e Adultos: uma proposta interdisciplinar para Biologia e Química.[Rio de Janeiro] 2011. 92 p. 29,7 cm (Mestrado Profissional em 
Ensino de Ciências/IFRJ, M.Sc., Ensino, 2011). Dissertação - Instituto Federal de Educação, Ciência e Tecnologia do Rio de Janeiro, PROPEC.

COSTOLDI, R.; POLINARSKI, C. A. Utilização de recursos didáticos- pedagógicos na motivação da aprendizagem. I Simpósio Internacional de Ensino e Tecnologia. 2009.

FAZENDA, I. C. A. (org.). O que é interdisciplinaridade? São Paulo: Cortez, 2008.

FREIRE, P. Pedagogia da autonomia: saberes necessários à prática educativa. 43. ed., São Paulo: Paz e Terra, 1996.

GIL, A. C.. Como elaborar projetos de pesquisa. 4.ed.-SãoPaulo: Atlas,2002.

MARCONI, M A. LAKATOS, E. M. Metodologia cientifica. 5.ed.4.reimpr- São Paulo: Atlas,2010.

OLIVEIRA, E. Interdisciplinaridade. $2010 . \quad$ Disponível em: http://www.infoescola.com/pedagogia/interdisciplinaridade. Acessado dia 15/04/2010

PELIZZARI, A. ; KRIEGL, M. L.; BARON, M. P.; FINCK, N.T. L.; DOROCINSKI, S. I.

TEORIA DA APRENDIZAGEM SIGNIFICATIVA SEGUNDO AUSUBEL. Rev. PEC, Curitiba, v.2, n.1, p.37-42, jul. 2001-jul. 2002. Disponível http://portaldoprofessor.mec.gov.br/storage/materiais/0000012381.pdf. Acessado dia 22/03/2014 